\title{
Knee jerk responses in infants at high risk for cerebral palsy: an observational EMG study
}

\author{
Elisa G. Hamer ${ }^{1,2}$, Linze J. Dijkstra' ${ }^{1}$, Siebrigje J. Hooijsma, ${ }^{1}$, Inge Zijdewind $^{3}$ and Mijna Hadders-Algra ${ }^{1}$
}

BACKGROUND: Following our clinical observation of tonic responses in response to the knee jerk in infants at very high risk for cerebral palsy (VHR infants), we systematically studied tonic responses, clonus, and reflex irradiation. We questioned (i) whether these responses occurred more often in VHR infants than in typically developing (TD) infants, and (ii) whether they were associated with abnormal general movement quality.

METHODS: Twenty-four VHR and 26 TD infants were assessed around 3 mo corrected age. Surface electromyograms of leg, trunk, neck, and arm muscles were recorded while eliciting the knee jerk. All assessments were video-recorded.

RESULTS:VHRinfants more often than TD infants showed tonic responses in the ipsilateral quadriceps and hamstring (MannWhitney $U_{i} P=0.0005$ and $P=0.0009$ ), clonus (Chi-square; $P=$ $0.0005)$ and phasic responses in the contralateral quadriceps and hamstring (Mann-Whitney $U_{;} P=0.002$ and $P=0.0003$, respectively). Widespread reflex irradiation occurred in VHR and TD infants. Definitely abnormal general movements and stiff movements were associated with tonic responses (MannWhitney $U ; P=0.0005, P=0.007$, respectively) and clonus (Mann-Whitney $U ; P=0.003$ and $P=0.0005$ ) in the ipsilateral quadriceps.

CONCLUSION: Similar to clonus, tonic responses may be regarded as a marker of a loss of supraspinal control. Reflex irradiation primarily is a neurodevelopmental phenomenon of early ontogeny.

O ne of the most well known items of the neurological examination is the knee jerk, i.e., the patellar tendon reflex. A tap on the patellar ligament rapidly stretches the quadriceps muscle. The muscle spindles signal the stretch and activate motoneurons in the spinal cord via a direct synaptic connection, which causes the quadriceps muscle to contract. In adults, the afferent fibers also activate inhibitory interneurons, which in turn inhibit the motoneurons of the antagonist muscles.

Stretch reflex activity in infants differs from that in adults $(1,2)$. First, newborn infants may show reciprocal excitation, i.e., electromyography (EMG) activity at monosynaptic latencies in the antagonist muscle in response to a tendon tap $(1,3,4)$. Second, infants may demonstrate reflex irradiation: activity in nearby muscles other than the agonist-antagonist pair in response to a tendon tap (3-5). The occurrence of reciprocal excitation and reflex irradiation decreases with increasing age $(2,4)$. In children with cerebral palsy, both reciprocal excitation and reflex irradiation persist during development $(2,4,6)$.

In addition to the above-described phenomena, we clinically observed long-lasting contractions, multiphasic kicks, and contralateral responses when eliciting the knee jerk in some infants at high risk for cerebral palsy, participating in the LEARN2MOVE (L2M) 0-2 y study (7). To the best of our knowledge, long lasting, tonic responses after tapping the quadriceps tendon have not been studied before in infancy. Tonic responses may be one of the components of hypertonia, one of the highly prevalent signs in children with cerebral palsy (8). However, evident hypertonia is rarely present in early infancy and a reliable diagnosis of cerebral palsy can be made from 18 mo onwards (8-10).

Hence, the primary aim of the present study was to systematically evaluate by means of surface EMG, (i) whether tonic responses, reflex irradiation (presence and extent), and clonus, i.e., repetitive responses, occur in young infants at very high risk for cerebral palsy (VHR infants) in response to the knee jerk, and (ii) if so, whether the responses of VHR infants differ from those of typically developing (TD) infants.

The secondary aim of the study was to assess whether possible differences in reflex activity in early infancy are associated with general movement quality, as general movement quality is the best clinical predictor for neuromotor development at this age (10). General movements are spontaneous movements that are characterized by variation; they are present until about 4 mo corrected age (11). Reduced complexity and variation (abnormal general movements) are associated with cerebral palsy (12). In children with abnormal general movements, the presence of stiff looking movements may further increase the risk for cerebral palsy (13). We hypothesized that general movement quality and movement stiffness

'Department of Pediatrics, Division of Developmental Neurology, University of Groningen, University Medical Center, Groningen, The Netherlands; ${ }^{2}$ Department of Neurology, Radboud University Medical Center, Nijmegen, The Netherlands; ${ }^{3}$ Department of Neuroscience, University of Groningen, University Medical Center, Groningen, The Netherlands. Correspondence: Mijna Hadders-Algra (m.hadders-algra@umcg.nl)

Received 4 September 2015; accepted 23 February 2016; advance online publication 25 May 2016. doi:10.1038/pr.2016.99 


\section{Articles | Hamer et al.}

are associated with reflex activity, since both general movements and stretch reflexes are modulated by supraspinal control (14), and movement stiffness may reflect increased stretch reflex activity (13).

\section{RESULTS}

The groups did not differ in age at assessment or sex (Table 1), but the VHR infants had a lower birth weight and gestational age at birth than TD infants. The median number of appropriate trials was 17 (range: 6-37). None of the EMG parameters were associated with the infant's corrected age at assessment (data not shown).

As a phasic response precedes a possible tonic response (Figure 1c), we first report the findings on the phasic responses, including reciprocal excitation and reflex irradiation. Next the results on tonic responses follow. Finally, the

Table 1. Infant characteristics

\begin{tabular}{lcc} 
& & TD $(n=26)$ \\
\hline Birth weight in grams (median + range) & $1,470(720-3,800)$ & $3,710(2,680-4,650)$ \\
Gestational age at birth in weeks (median + range) & $30.5(25.9-41.1)$ & $40.0(36.7-41.7)$ \\
Age at assessment, in months corrected age (median + range) & $2.9(1.0-4.9)$ & $3.0(2.6-3.8)$ \\
Boys/girls & $13 / 11$ & $14 / 12$ \\
Type of brain lesion & 4 & 0.0005 \\
Basal ganglia/thalamic lesion & 1 & - \\
Cortical infarction & 7 & 8 \\
Periventricular leukomalacia & 4 & $23.9(20.8-27.8)^{\mathrm{a}}$ \\
Posthemorrhagic porencephaly & $22.9(18.1-28.0)$ & 0.062 \\
No or nonsignificant lesion & \\
Length lower limb in cm (median + range)
\end{tabular}

aAnthropometric data are missing for one VHR infant due to technical problems.

TD, typically developing; VHR, very high risk for cerebral palsy.

a

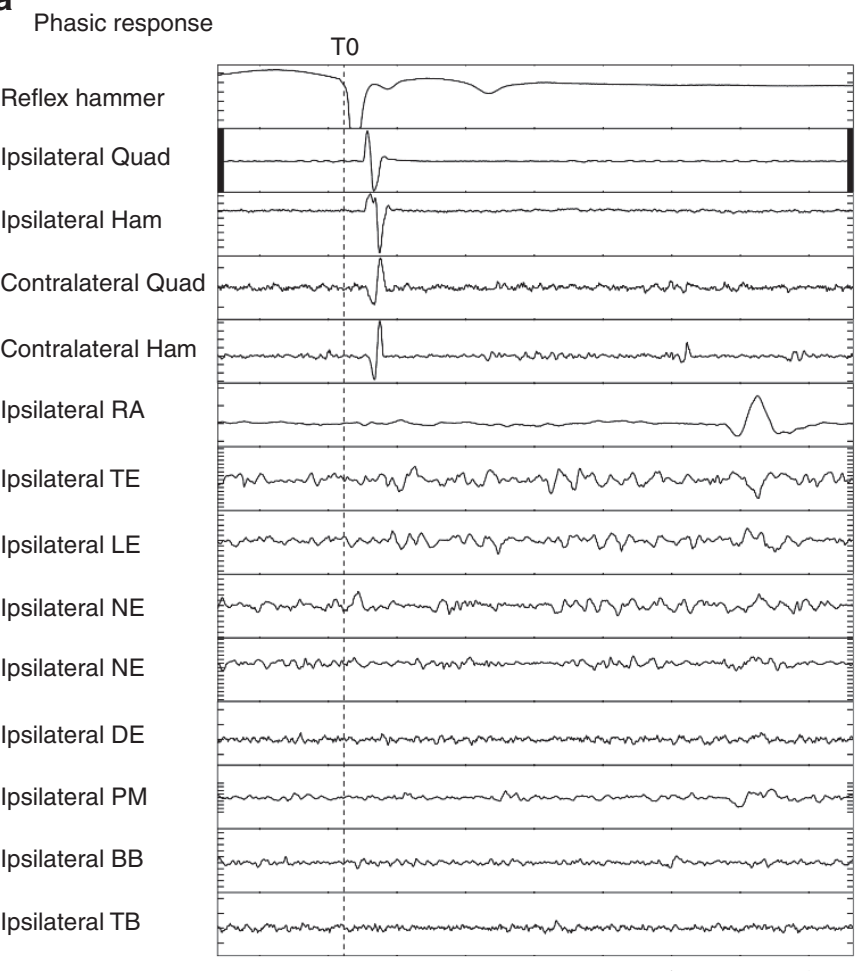

b

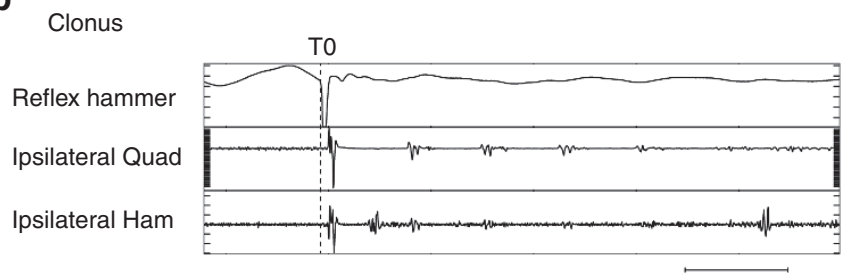

C

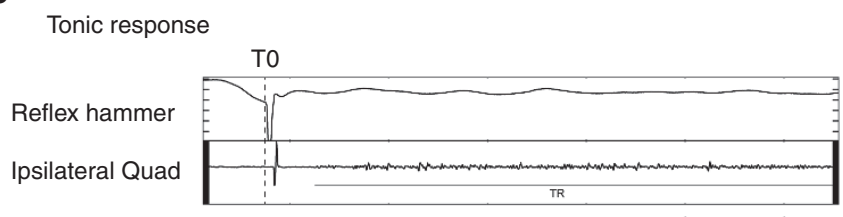

d

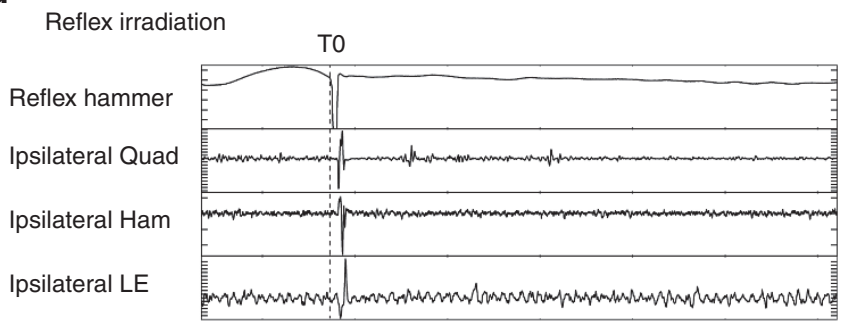

Figure 1. EMG analysis. EMG signals of reflex hammer and recorded muscles. T0 is indicated by the vertical dotted lines. The horizontal lines below the panels represent the duration of $100 \mathrm{~ms}$ (panel a) or $200 \mathrm{~ms}$ (panels $\mathbf{b}$-d). The amplitude units are indicated on the $y$-axes: the intervals between the small horizontal markers represent $25 \mu \mathrm{V}$. (a) Phasic responses in both ipsilateral and contralateral quadriceps and hamstring, (b) Clonus of the ipsilateral quadriceps and hamstring, (c) phasic response of the ipsilateral quadriceps, followed by a tonic response, (d) phasic responses of the ipsilateral quadriceps, hamstring, and LE. The figures represent single examples of TD (panel a) and VHR (panels b-d) infants. 
associations between general movement-quality and reflex activity are presented.

\section{Phasic Reflex Responses}

In both VHR and TD infants, we observed a phasic response of the ipsilateral quadriceps muscle in $100 \%$ of the trials. Response latencies of VHR and TD infants were similar (Table 2). Additionally, the ipsilateral hamstring muscle virtually always showed a phasic response (median: 100\%, range: 89-100\%).

VHR infants more often showed a phasic response in the contralateral quadriceps (VHR 63\% vs. TD 34\% MannWhitney $U ; P=0.002$ ) and contralateral hamstring (VHR 63\% vs. TD $40 \%$, Mann-Whitney $U ; P=0.003$ ) than TD infants.

In both groups, ipsilateral and contralateral phasic responses were occasionally observed in all other muscles in which EMG activity was recorded (Table 2); phasic responses were mainly noted in the rectus abdominis (median values: $12 \%$ ipsilateral, $4 \%$ contralateral) and lumbar extensor (median values: $11 \%$ ipsi- and contralateral). The frequencies of the irradiated phasic responses in VHR infants did not significantly differ from those in TD infants.

The latencies of the phasic responses of the ipsilateral and contralateral quadriceps and hamstring and those of the phasic responses of the other muscles of VHR infants did not differ from those of TD infants (Table 2).

VHR infants more often showed at least once a series of repetitive phasic responses in the ipsilateral quadriceps than TD infants did (18 out of 23 infants and 4 out of 26, respectively; Chi-square; $P=0.0005)$. VHR infants showed a repetitive phasic response in $25 \%$ (median value) of the trials (range: 0-47\%), whereas TD infants seldom showed a repetitive phasic response (median: 0\%, range: $0-21 \%$; Mann-Whitney $U$; $P=0.0005$ ). VHR infants showed up to four repeats (i.e., five phasic responses) per trial, whereas the four TD infants never showed more than one repeat (two phasic responses).

\section{Tonic Reflex Responses}

The observed tonic responses reflected a continuous interference pattern, indicating activity of several motor units (Figure 1c). More VHR infants (22 out of 23) than TD infants (7 out of 26) showed at least one tonic response in the ipsilateral quadriceps (Chi-square; $P=0.0005$ ). VHR infants showed a tonic response in the ipsilateral quadriceps in 34\% of the trials (range: 0-95\%); significantly more often than TD infants did (median: $0 \%$, range: $0-43 \%$; Table 3). A tonic response of the ipsilateral hamstring was also more often observed in VHR infants (Table 3). The onset latencies and duration of the tonic responses did not differ between VHR and TD infants (Table 3). Tonic responses generally occurred after a brief electrical silence following the phasic response (Figure 1c). Tonic responses lasted on average 1.1 (ipsilateral quadriceps), 0.7 (ipsilateral hamstring), 1.2 (contralateral quadriceps), and $0.9 \mathrm{~s}$ (contralateral hamstring).

\section{Associations Between General Movement Quality and Knee Jerk Responses}

One TD infant showed normal-optimal general movements, 15 TD infants had normal-suboptimal general movements,
14 infants had mildly abnormal general movements ( 9 TD, 5 VHR), and 20 infants had definitively abnormal general movements (1 TD, 19 VHR). Note that the data of the infants with normal-optimal and normal-suboptimal general movements were pooled.

General movement quality was not associated with the occurrence and the relative latencies of phasic responses. However, infants with worse general movement quality showed more often repetitive phasic responses (Spearman's $\rho=$ $0.507, P=0.0005)$. General movement quality was also related to the occurrence of tonic responses: infants with worse general movement quality showed more often a tonic response in the ipsilateral quadriceps (Spearman's $\rho=0.659, P=0.0005$ ). The association between general movement quality and knee jerk responses was brought about in particular by definitely abnormal general movements: infants with definitely abnormal general movements more often showed repetitive phasic responses (definitely abnormal general movements 19\% of the trials vs. nondefinitely abnormal general movements $0 \%$, Mann-Whitney $U ; P=0.003$ ) and tonic responses in the ipsilateral quadriceps (definitely abnormal general movement $34 \%$ of the trials vs. nondefinitely abnormal general movements $0 \%$, Mann-Whitney $U ; P=0.0005$, Figure 2).

Nineteen infants showed stiff looking movements (further labeled as stiff movements): 14 of them had definitely abnormal general movements, 16 were VHR infants. Infants with stiff movements had shorter relative phasic response onset latencies of the ipsilateral hamstring (median stiff movements 1.34 vs. no stiff movements 1.52 , Mann-Whitney $U ; P=0.004$ ) and showed more often a tonic response in the ipsilateral quadriceps (median 25 vs. $0 \%$, Mann-Whitney $U$; $P=0.003$ ) than infants without stiff movements. Infants with stiff movements showed significantly more often repetitive phasic responses (15 out of 18 infants) than infants without stiff movements (7 out of 31 infants; Chi-square, $P=0.0005$ ).

\section{DISCUSSION}

The present study indicated that around 3 mo corrected age, knee jerk responses in infants at very high risk for cerebral palsy differ from those in typically developing infants: VHR infants more often than TD infants showed (i) tonic responses in the ipsilateral quadriceps and hamstring muscles, (ii) phasic responses in the contralateral quadriceps and hamstring muscles, and (iii) repetitive phasic responses (clonus) in the ipsilateral quadriceps. Widespread reflex irradiation, present in trunk, neck, and arm muscles, occurred every now and then in VHR and TD infants. Definitely, abnormal general movements and stiff movements were associated with more tonic and clonic responses in the ipsilateral quadriceps.

\section{Tonic Responses}

All but one VHR infant showed tonic responses in the ipsilateral quadriceps, whereas TD infants seldom exhibited a tonic response. We hypothesize that the occurrence of continuous stretch reflex activity was brought about by so-called persistent inward currents (PICs). PICs are the consequence of slowly inactivating (mainly) calcium and sodium channels 
Articles | Hameretal.

Table 2. EMG knee jerk parameters-phasic responses

\begin{tabular}{|c|c|c|c|c|c|c|c|}
\hline \multirow[b]{2}{*}{ Relative onset latency PR } & \multicolumn{3}{|c|}{ TD } & \multicolumn{3}{|c|}{ VHR } & \multirow[t]{2}{*}{$P$ value } \\
\hline & Median & Range & $N$ & Median & Range & $N$ & \\
\hline Ipsi Quadriceps & 1.26 & $0.95-1.76$ & 26 & 1.26 & $0.91-1.69$ & 22 & 0.725 \\
\hline Ipsi Hamstring & 1.48 & $1.07-2.11$ & 26 & 1.41 & $1.06-1.78$ & 23 & 0.149 \\
\hline Contra Quadriceps & 1.79 & $1.43-2.62$ & 23 & 1.85 & $1.44-3.90$ & 23 & 0.249 \\
\hline \multirow[t]{2}{*}{ Contra Hamstring } & 1.77 & $1.26-3.03$ & 25 & 1.79 & $1.29-2.46$ & 22 & 0.522 \\
\hline & \multicolumn{3}{|c|}{ TD } & \multicolumn{3}{|c|}{ VHR } & $P$ value \\
\hline Ipsilateral irradiation (\%) & Median & Range & $N$ & Median & Range & $N$ & \\
\hline Deltoid & 0 & $0-25.0$ & 24 & 0 & $0-22.2$ & 20 & 0.247 \\
\hline Pectoralis major & 0 & $0-16.7$ & 25 & 0 & $0-28.6$ & 21 & 0.022 \\
\hline Biceps brachii & 0 & $0-14.3$ & 25 & 0 & $0-20.0$ & 20 & 0.742 \\
\hline Triceps brachii & 0 & $0-33.3$ & 24 & 0 & $0-8.3$ & 20 & 0.141 \\
\hline Neckflexor & 0 & $0-20.0$ & 25 & 0 & $0-28.6$ & 20 & 0.368 \\
\hline Neck extensor & 7.1 & $0-22.2$ & 25 & 0 & $0-60.0$ & 19 & 0.659 \\
\hline Rectus abdominis & 11.1 & $0-40.0$ & 26 & 12.5 & $0-60.0$ & 20 & 0.676 \\
\hline Thoracal extensor & 0 & $0-44.4$ & 24 & 0 & $0-80.0$ & 21 & 0.163 \\
\hline \multirow[t]{2}{*}{ Lumbar extensor } & 8.33 & $0-90.0$ & 23 & 15.4 & $0-58.3$ & 21 & 0.490 \\
\hline & \multicolumn{3}{|c|}{ TD } & \multicolumn{3}{|c|}{ VHR } & $P$ value \\
\hline Contralateral irradiation (\%) & Median & Range & $N$ & Median & Range & $N$ & \\
\hline Deltoid & 0 & $0-22.2$ & 23 & 0 & $0-33.3$ & 18 & 0.820 \\
\hline Pectoralis major & 0 & $0-33.3$ & 25 & 0 & $0-22.2$ & 18 & 0.712 \\
\hline Biceps brachii & 0 & $0-16.7$ & 24 & 0 & $0-33.3$ & 17 & 0.181 \\
\hline Triceps brachii & 0 & $0-50.0$ & 23 & 0 & $0-0$ & 18 & 0.205 \\
\hline Neck flexor & 0 & $0-16.7$ & 24 & 0 & $0-11.1$ & 16 & 0.373 \\
\hline Neck extensor & 0 & $0-42.9$ & 24 & 0 & $0-33.3$ & 16 & 0.455 \\
\hline Rectus abdominis & 8.3 & $0-33.3$ & 25 & 0 & $0-23.1$ & 17 & 0.848 \\
\hline Thoracal extensor & 0 & $0-22.2$ & 23 & 0 & $0-44.4$ & 18 & 0.638 \\
\hline Lumbar extensor & 18.2 & $0-75.0$ & 25 & 10.1 & $0-66.7$ & 18 & 0.929 \\
\hline \multirow{2}{*}{$\begin{array}{l}\text { Relative onset latency ipsilateral } \\
\text { irradiation }\end{array}$} & \multicolumn{3}{|c|}{ TD } & \multicolumn{3}{|c|}{ VHR } & $P$ value \\
\hline & Median & Range & $N$ & Median & Range & $N$ & \\
\hline Deltoid & 2.72 & - & 1 & 2.61 & $2.20-3.01$ & 2 & 1.000 \\
\hline Pectoralis major & 1.98 & $1.01-2.64$ & 4 & 2.45 & $1.65-4.77$ & 10 & 0.282 \\
\hline Biceps brachii & 1.85 & $1.26-4.67$ & 3 & 2.30 & $1.36-3.83$ & 3 & 1.000 \\
\hline Triceps brachii & 1.96 & $0.66-2.40$ & 6 & 1.85 & - & 1 & 0.517 \\
\hline Neck flexor & 1.77 & $1.01-2.65$ & 10 & 1.17 & $0.81-2.96$ & 5 & 0.206 \\
\hline Neck extensor & 1.64 & $1.06-3.03$ & 13 & 1.53 & $1.06-3.16$ & 7 & 0.877 \\
\hline Rectus abdominis & 1.85 & $0.45-4.29$ & 16 & 1.80 & $1.26-3.65$ & 14 & 0.779 \\
\hline Thoracal extensor & 1.87 & $1.76-2.88$ & 6 & 2.12 & $0.90-3.02$ & 9 & 1.000 \\
\hline Lumbar extensor & 1.72 & $1.05-3.06$ & 14 & 1.53 & $0.73-4.83$ & 12 & 0.899 \\
\hline \multirow{2}{*}{$\begin{array}{l}\text { Relative onset latency } \\
\text { contralateral irradiation }\end{array}$} & \multicolumn{3}{|c|}{ TD } & \multicolumn{3}{|c|}{ VHR } & \multirow[t]{2}{*}{$P$ value } \\
\hline & Median & Range & $N$ & Median & Range & $N$ & \\
\hline Deltoid & 1.92 & $1.61-2.77$ & 4 & 2.41 & $1.13-2.86$ & 4 & 0.686 \\
\hline Pectoralis major & 2.04 & $1.39-2.56$ & 9 & 2.02 & $1.87-2.18$ & 7 & 1.000 \\
\hline Biceps brachii & 1.93 & $1.31-2.45$ & 3 & 2.18 & $1.17-3.45$ & 5 & 0.857 \\
\hline Triceps brachii & 2.46 & $1.77-3.15$ & 2 & - & & 0 & - \\
\hline Neck flexor & 1.67 & $0.80-4.01$ & 7 & 2.29 & $1.12-3.09$ & 3 & 0.517 \\
\hline Neck extensor & 1.43 & $0.77-3.04$ & 10 & 1.74 & $1.53-2.99$ & 5 & 0.254 \\
\hline Rectus abdominis & 1.89 & $1.33-3.51$ & 13 & 2.82 & $0.82-3.87$ & 8 & 0.374 \\
\hline Thoracal extensor & 2.50 & $2.48-2.65$ & 4 & 1.50 & $0.89-2.12$ & 2 & 0.133 \\
\hline Lumbar extensor & 1.47 & $0.89-2.22$ & 14 & 1.14 & $0.64-3.50$ & 11 & 0.373 \\
\hline
\end{tabular}

EMG, electromyography; PR, phasic response; TD, typically developing; VHR, very high risk for cerebral palsy. 
Table 3. EMG knee jerk parameters-tonic responses

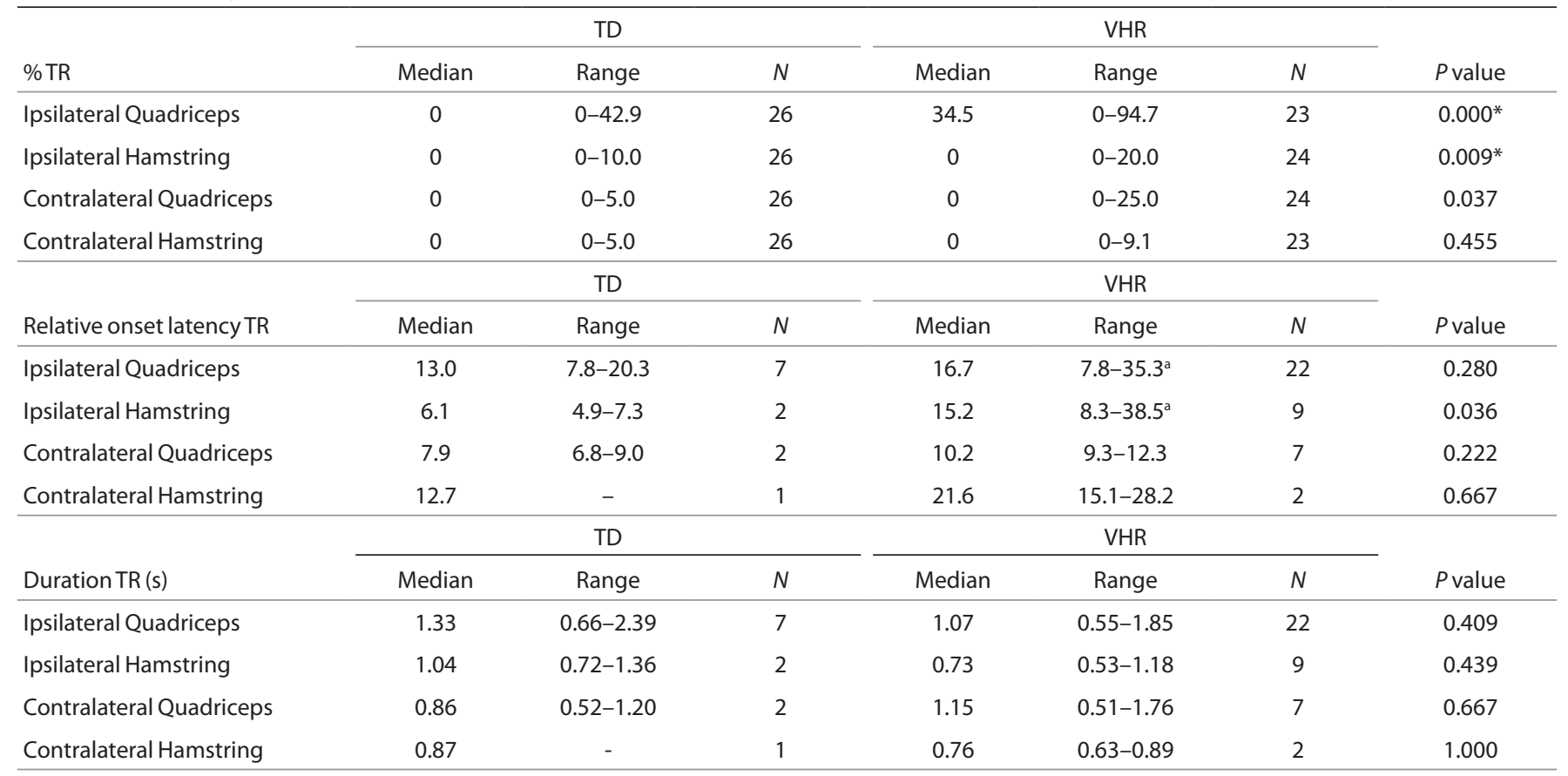

${ }^{a}$ According to our criteria, a TR had to start within $150 \mathrm{~ms}$ after the PR. As TR onset latency was calculated from T0, values may exceed $150 \mathrm{~ms}$. One child showed TRs preceded by repetitive PRs, resulting in TR onset values above $300 \mathrm{~ms}$.

*Mann-Whitney $U ; P<0.01$.

EMG, electromyography; TD, typically developing; TR, tonic response; VHR, very high risk for cerebral palsy.

in the presence of neuromodulatory input (e.g., serotonine). PIC's may therefore produce long-lasting self-sustained firing of motoneurons (bistable behavior). Together with the ability to amplify synaptic input, PICs do increase motoneuron excitability (14). The input associated with phasic muscle stretch may therefore activate the PICs, which continue to be active once the excitatory synaptic input has passed (15). Indeed, the tonic responses resemble motoneuronal output induced by the PICs described in neonatal mice (16). An additional explanation is that the phasic response itself induced the tonic response: the relief of stretch can provoke a powerful postexcitatory contraction (17). The changed supraspinal inhibition in VHR infants is likely to attribute to this so-called "rebound phenomenon".

\section{Phasic Responses: Irradiation and Repetition}

Our data indicate that substantial reflex irradiation is present in 3-mo-old infants with and without increased risk for developmental disorders, especially to homologous muscles on the contralateral side. The latter phenomenon has, to our knowledge, not been described before. The irradiation of reflex activity to many other muscles than the quadriceps might be explained by various mechanisms. First, the physiological hyperexcitability of the spinal circuitries, which is intensively present at term age and gradually wanes with increasing age, may play a role. This hyperexcitability is, for example, expressed by lower thresholds for the stretch reflex (3), by the presence of crossed adductor responses when eliciting the knee jerk (18) and the presence of reciprocal excitation in TD newborns (5).

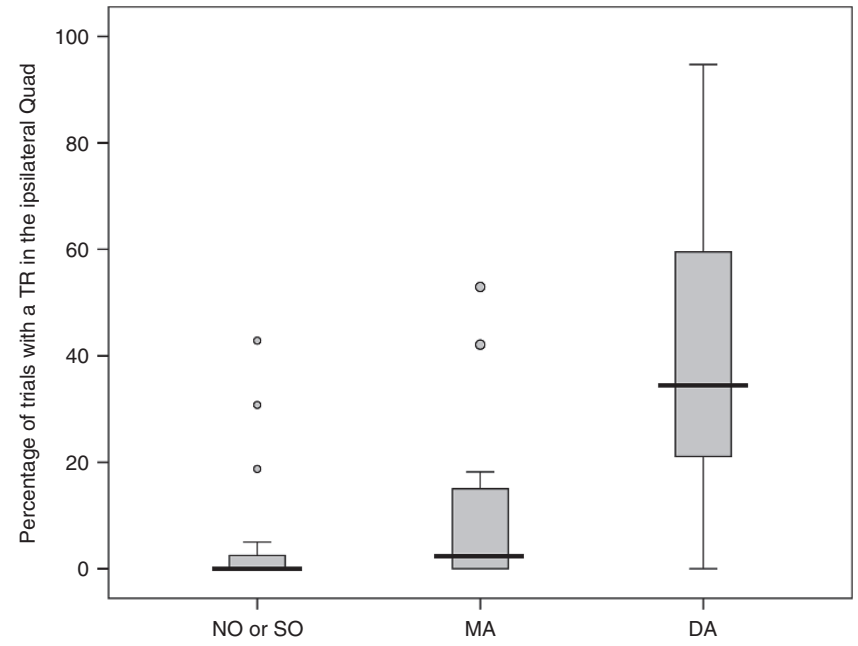

Figure 2. General movement-quality and the frequency of tonic responses. Data are presented as median values (horizontal bars), interquartile ranges (boxes), and ranges (vertical lines) with outliers (circles).

Second, increased sensitivity of muscles spindles, motoneuron pools, and motor units may contribute (1). A third factor may be the redundancy of excitatory projections to motoneurons of nonhomonymous muscles; these projections disappear during development (3).

The frequent occurrence of phasic responses in the homologous contralateral leg muscles could be related to the ontogeny of the central pattern generators for locomotion. Animal studies indicate that these central pattern generators initially 
generate synchronous motor bursts on both sides of the lumbar spinal cord. During development, the output changes into a burst pattern that alternates between left and right, due to maturation of inhibitory connections between the two sides (19). The phenomenon of reflex irradiation in the contralateral quadriceps and hamstring, as well as in the rectus abdominis and lumbar extensor muscles, suggests the presence of excitatory connections across one or more spinal levels (5).

An additional increase of excitability of the spinal circuitries due to reduced supraspinal inhibition in VHR infants could explain the higher prevalence of repetitive and contralateral phasic responses in VHR infants than in TD infants (1).

\section{Movement Quality and Knee Jerk Responses}

Definitely, abnormal general movements were associated with the presence of tonic responses and clonus. This underlines the notion that definitely abnormal general movements point to a serious loss of supraspinal control. Mildly abnormal general movements showed the association with tonic responses to a minor extent, suggesting that mildly abnormal general movements reflect indeed the presence of milder forms of supraspinal dysfunction (20). General movement-quality was not associated with reflex irradiation; this emphasizes the typical nature of reflex irradiation during early ontogeny. The association between stiff movements and tonic responses strengthens the assumption that a stiff movement character reflects increased stretch reflex activity (13).

\section{Methodological Considerations}

This is, to our knowledge, the first study that compared EMG reflex responses of VHR infants with that of TD infants at 3 mo corrected age. The age of the infants allowed us to study associations between reflex responses and general movement quality. Another strength of the study is the blinded EMG analysis. In addition, EMG analysis was performed by the author E.G.H. and general movement classification by the author M.H.A.. Both were unaware of the findings of each other.

The heterogeneity within the group of VHR infants is a limitation of this study. The relatively small sample size did not allow us to examine differences within the VHR infants, e.g., to investigate the effect of the type of brain lesion. Another limitation is the manual application of the tap, implying that the force and frequency of the stimulus varied. However, we only included trials in which a clear kick of the leg was observed. Moreover, we considered this method to be infant-friendly and in proper correspondence with a standard clinical examination.

This study aimed to evaluate whether there were any objective differences in knee jerk responses between VHR and TD infants. Future research should address the question whether the presence of tonic responses and clonus also is associated with neuromotor outcome, including the diagnosis of cerebral palsy.

\section{Concluding Remarks}

In conclusion, this study indicates that knee jerk responses in VHR infants differ from those in TD infants: VHR infants
Table 4. General movement quality

\begin{tabular}{lccc}
\hline Classification & Complexity & Variation & Fluency \\
\hline Normal-optimal & +++ & +++ & + \\
Normal-suboptimal & ++ & ++ & - \\
Mildly abnormal & + & + & - \\
Definitely abnormal & $\pm /-$ & $\pm /-$ & - \\
\hline
\end{tabular}

Classification according to Hadders-Algra 2004 (21).

Complexity and variation: $+++=$ abundantly present,$++=$ sufficiently present,$++=$ present, but insufficiently, $\pm=$ virtually absent, $-=$ absent. Fluency (the least important aspect of GM-assessment): + = present, - = absent.

more often showed tonic responses, clonus, and reflex irradiation to contralateral leg muscles. Especially, the presence of tonic responses and clonus may be regarded as a marker of a loss of supraspinal control, whereas reflex irradiation primarily is a neurodevelopmental phenomenon of early ontogeny. Future research should address the prognostic significance of tonic responses and clonus for neuromotor outcome, including spasticity. Such information is valuable in the early identification and follow-up of VHR infants, especially with regard to the development and treatment of contractures and deformities.

\section{METHODS}

\section{Participants}

We included 24 VHR and 26 TD infants. The VHR infants participated in the L2M 0-2 y study, a randomized controlled trial on the effect of early intervention in infants at high risk for cerebral palsy (7). Inclusion criteria of the L2M project were age at enrolment 1 to 9 mo corrected age and the presence of at least one of the following conditions: (i) cystic periventricular leukomalacia, (ii) parenchymal lesion of the brain, (iii) neonatal hypoxic-ischaemic encephalopathy (Sarnat 2 or 3) with brain lesions on MRI, and iv) neurological dysfunctions suggestive of the development of cerebral palsy (7). For the present study, we included all infants who were enrolled in the L2M project before the age of 5 mo corrected age. We used their assessment that occurred most closely to 3 mo corrected age: for 20 infants, this was the baseline assessment, for four infants the second assessment. TD infants were recruited by nurses who perform the neonatal heel prick or via personal contacts: none of them had prenatal, perinatal or neonatal complications. TD infants were assessed around 3 mo corrected age. The parents gave informed consent. The data collection was approved by the Medical Ethics Committee of the University Medical Center Groningen (VHR infants trial number NTR 1428; TD infants trial number NL39954.042.12).

\section{Procedures: Video and EMG Recording}

The assessment was performed at the infant's home. The session consisted of a videotaped general movement assessment and examination of the knee jerk reflex. A general movement assessment comprises a recording of at least $5 \mathrm{~min}$ of spontaneous motor behavior in supine position; the knee jerk was elicited approximately 10 times on each side.

In order to study the responses of the knee jerk, bipolar surface electrodes with an inter-electrode distance of $14 \mathrm{~mm}$ were placed over the bellies of the right and left quadriceps and right and left hamstring (to evaluate ipsilateral reciprocal activity and contralateral responses). Additional electrodes were placed on the following muscles on the right side of the body: rectus abdominis, thoracic extensor, lumbar extensor, sternocleidomastoid (neck flexor), neck extensor, deltoid, pectoralis major, biceps brachii, and triceps brachii to examine reflex irradiation at various distances from the stimulus. Surface EMG signals and reflex hammer accelerations were continuously recorded by means of an electro-physiological front-end amplifier (Twente 
Medical Systems International, Enschede, the Netherlands) at a sampling rate of 2,000 Hz.

\section{Data Analysis}

We used the general movement video-recordings to classify the quality of the general movements on the basis of Gestalt perception into normal-optimal, normal-suboptimal, mildly abnormal, or definitely abnormal (21). This categorization is mainly based on the degree of variation and complexity of the infant's spontaneous motor behavior in supine position (Table 4). Since normal-optimal general movements are relatively rare and in the present study have no additional significance (22), we pooled the data of children with normal-optimal and normal-suboptimal general movements. The assessment has a good reliability and a high predictive validity (23). Furthermore, we evaluated the presence of stiff movements according to Hamer et al. (13). The last author, M.H.A., performed the general movement classification. She was aware of study group membership, but she was masked for knee jerk responses and clinical perinatal characteristics of the infants.

The EMG signals were analyzed with the software package PedEMG (Developmental Neurology, University Medical Center Groningen, The Netherlands) (24). First, all knee jerk videos were analyzed (i) to include only trials in which a clear kick of the leg was observed in response to the tendon tap, and (ii) to determine on which side (right or left patellar tendon) the tap was applied. Next, the EMGs were analyzed without video and without any information of the infant such as name, age, and study group. The tap-signal from the reflex hammer was used to define T0 of the knee jerk latency (Figure 1). Onset times of phasic responses phasic responses and tonic responses were determined with the use of the model-based algorithm of Staude and Wolf, which detects significant changes in muscle activity (bursts) (24). Responses were considered a phasic response $(2,5,25)$ if they (i) occurred within $40 \mathrm{~ms}$ after T0, (ii) lasted maximally $15 \mathrm{~ms}$, (iii) were bi- or triphasic, and (iv) significantly differed from background activity and muscle activity prior to tap application (Figure 1a). The presence and the number of repeats of repetitive phasic responses (clonus) were recorded (Figure 1b). Reponses were considered as tonic responses if they (i) started within $150 \mathrm{~ms}$ after a phasic response, (ii) lasted at least $500 \mathrm{~ms}$, and (iii) visual inspection indicated continued activity of a similar intensity (Figure 1c); see also refs. $(26,27)$ ). Note that the terms phasic and tonic do not imply that in phasic responses only so-called fast motor units are involved and in tonic responses only slow motor units.

We calculated the percentage of trials with occurrence of a phasic response for the ipsilateral quadriceps (i.e., using the right quadriceps when a tap was applied on the right side, and the left quadriceps when a tap was applied on the left side), as well as for the ipsilateral hamstring, contralateral quadriceps, and contralateral hamstring. We also computed for the ipsilateral and contralateral quadriceps and hamstring the (i) mean relative onset latency of the phasic response, (ii) percentage of trials with occurrence of a tonic response, (iii) mean onset latency of a tonic response, and (iv) mean duration of a tonic response. Relative latencies were calculated by dividing the absolute onset times by the length of the infant's lower leg, as a proxy for body length (28). We assessed the infant's lower leg length by measuring the distance between the lateral tibial condyle and the lateral malleolus with the help of SIMI Motion 3D (SIMI Motion Systems, Unterschleißheim, Germany) (Table 1).

In addition, we calculated for each of the other muscles the percentage of trials with occurrence of a phasic response plus the mean relative onset latency of the phasic response. We differentiated between ipsilateral irradiation (i.e., phasic response in the trials with a tap applied on the right side, e.g., Figure 1d) and contralateral irradiation (phasic responses after a tap on the left side). Parameters were only computed if at least five proper trials were available for the analysis.

\section{Statistical Analysis}

SPSS package version 20.0 (IBM Corporation, Armonk, NY) was used for statistical analysis. Nonparametric tests were performed since the data were not normally distributed. $P$ values $<0.01$ were considered to be statistically significant.

\section{ACKNOWLEDGMENTS}

We are grateful to all infants and their families for participating in this study. We would like to thank Jeroen $\mathrm{R}$ Vermeulen, for classification of the brain imaging data and Arend F. Bos, for his critical comments on a previous version of this manuscript. We thank Anneke Kracht for her skillful assistance in the preparation of the figures.

\section{STATEMENT OF FINANCIAL SUPPORT}

This study is part of the national LEARN 2 MOVE research program and is financially supported by ZonMW, Johanna Kinderfonds, Stichting Rotterdams Kinderrevalidatiefonds Adriaanstichting, Revalidatiefonds, Phelps Stichting, Revalidatie Nederland, and the Nederlandse Vereniging van Revalidatieartsen. E.G.H. was financially supported by the Junior Scientific Masterclass Groningen and the graduate school of behavior and cognitive neuroscience. None of the funders were involved in study design, data collection, data analysis, manuscript preparation or publication decisions.

\section{Disclosure: None declared.}

\section{REFERENCES}

1. Myklebust BM, Gottlieb GL, Agarwal GC. Stretch reflexes of the normal infant. Dev Med Child Neurol 1986;28:440-9.

2. O’Sullivan MC, Miller S, Ramesh V, et al. Abnormal development of biceps brachii phasic stretch reflex and persistence of short latency heteronymous reflexes from biceps to triceps brachii in spastic cerebral palsy. Brain 1998;121 (Pt 12):2381-95.

3. O'Sullivan MC, Eyre JA, Miller S. Radiation of phasic stretch reflex in biceps brachii to muscles of the arm in man and its restriction during development. J Physiol 1991;439:529-43.

4. Leonard CT, Hirschfeld H. Myotatic reflex responses of non-disabled children and children with spastic cerebral palsy. Dev Med Child Neurol 1995;37:783-99.

5. Myklebust BM, Gottlieb GL. Development of the stretch reflex in the newborn: reciprocal excitation and reflex irradiation. Child Dev 1993;64:103645.

6. Myklebust BM, Gottlieb GL, Penn RD, Agarwal GC. Reciprocal excitation of antagonistic muscles as a differentiating feature in spasticity. Ann Neurol 1982;12:367-74.

7. Hielkema T, Hamer EG, Reinders-Messelink HA, et al. LEARN 2 MOVE $0-2$ years: effects of a new intervention program in infants at very high risk for cerebral palsy; a randomized controlled trial. BMC Pediatr 2010;10:76.

8. Surveillance of cerebral palsy in Europe (SCPE): a collaboration of cerebral palsy surveys and registers. Dev Med Child Neurol 2000; 42: 816-24

9. Heinen F, Baxter P. Cerebral Palsy. In: Kennedy C, ed. Principles and Practice of Child Neurology in Infancy. London: Mac Keith Press, 2012.

10. Hadders-Algra M. Early diagnosis and early intervention in cerebral palsy. Front Neurol 2014;5:185.

11. Einspieler C, Prechtl HF. Prechtl's assessment of general movements: a diagnostic tool for the functional assessment of the young nervous system. Ment Retard Dev Disabil Res Rev 2005;11:61-7.

12. Prechtl HF, Einspieler C, Cioni G, Bos AF, Ferrari F, Sontheimer D. An early marker for neurological deficits after perinatal brain lesions. Lancet 1997;349:1361-3.

13. Hamer EG, Bos AF, Hadders-Algra M. Assessment of specific characteristics of abnormal general movements: does it enhance the prediction of cerebral palsy? Dev Med Child Neurol 2011;53:751-6.

14. Heckman CJ, Johnson M, Mottram C, Schuster J. Persistent inward currents in spinal motoneurons and their influence on human motoneuron firing patterns. Neuroscientist 2008;14:264-75.

15. Heckman CJ, Mottram C, Quinlan K, Theiss R, Schuster J. Motoneuron excitability: the importance of neuromodulatory inputs. Clin Neurophysiol 2009;120:2040-54.

16. Zhong G, Masino MA, Harris-Warrick RM. Persistent sodium currents participate in fictive locomotion generation in neonatal mouse spinal cord. J Neurosci 2007;27:4507-18.

17. Del Castillo-Nicolau J, Schweitzer A. Reflex rebound in extensor muscles. Q J Exp Physiol 1949;35:1-10.

18. Volpe JJ. Neurology of the Newborn. 5th edn. Philadelphia: Saunders Elsevier, 2008:132. 


\section{Articles | Hameretal.}

19. Gackière F, Vinay L. Serotonergic modulation of post-synaptic inhibition and locomotor alternating pattern in the spinal cord. Front Neural Circuits 2014;8:102.

20. Hadders-Algra M. Putative neural substrate of normal and abnormal general movements. Neurosci Biobehav Rev 2007;31:1181-90.

21. Hadders-Algra M, Mavinkurve-Groothuis AM, Groen SE, Stremmelaar EF, Martijn A, Butcher PR. Quality of general movements and the development of minor neurological dysfunction at toddler and school age. Clin Rehabil 2004;18:287-99.

22. Hadders-Algra M. General movements: A window for early identification of children at high risk for developmental disorders. J Pediatr 2004;145(2 Suppl):S12-8.

23. Heineman KR, Hadders-Algra M. Evaluation of neuromotor function in infancy-A systematic review of available methods. J Dev Behav Pediatr 2008;29:315-23.
24. van Balen LC, Dijkstra LJ, Hadders-Algra M. Development of postural adjustments during reaching in typically developing infants from 4 to 18 months. Exp Brain Res 2012;220:109-19.

25. Mc Donough SM, Clowry GJ, Miller S, Eyre JA. Reciprocal and Renshaw (recurrent) inhibition are functional in man at birth. Brain Res 2001;899:66-81.

26. Toft E, Sinkjaer T, Andreassen S, Larsen K. Mechanical and electromyographic responses to stretch of the human ankle extensors. J Neurophysiol 1991;65:1402-10.

27. Jobin A, Levin MF. Regulation of stretch reflex threshold in elbow flexors in children with cerebral palsy: a new measure of spasticity. Dev Med Child Neurol 2000;42:531-40.

28. Stevenson RD. Use of segmental measures to estimate stature in children with cerebral palsy. Arch Pediatr Adolesc Med 1995;149: 658-62. 